\title{
Aircraft measurements of microphysical properties of subvisible cirrus in the tropical tropopause layer
}

\author{
R. P. Lawson ${ }^{1}$, B. Pilson ${ }^{1}$, B. Baker ${ }^{1}$, Q. Mo ${ }^{1}$, E. Jensen ${ }^{2}$, L. Pfister ${ }^{2}$, and P. Bui ${ }^{2}$ \\ ${ }^{1}$ SPEC Incorporated, Boulder, CO, USA \\ ${ }^{2}$ NASA Ames Research Center, Moffett Field, CA, USA
}

Received: 23 March 2007 - Published in Atmos. Chem. Phys. Discuss.: 10 May 2007

Revised: 8 October 2007 - Accepted: 20 February 2008 - Published: 18 March 2008

\begin{abstract}
Subvisible cirrus (SVC) clouds are often observed within the tropical tropopause layer (TTL). Some studies suggest that SVC has a significant impact on the earth radiation budget. The Costa Rica Aura Validation Experiment (CR-AVE) sponsored by the National Aeronautics and Space Administration (NASA) took place near San Jose, Costa Rica from 14 January-15 February 2006. The NASA WB-57F sampled SVC in the TTL from $-75^{\circ} \mathrm{C}$ to $-90^{\circ} \mathrm{C}$ with an improved set of cloud particle probes. The first digital images of ice particles in the TTL are compared with replicator images of ice particles collected in 1973 by a WB-57F in the TTL. The newer measurements reveal larger particles, on the order of $100 \mu \mathrm{m}$ compared with $<50 \mu \mathrm{m}$ from the earlier measurements, and also different particle shapes. The 1973 particles were mainly columnar and trigonal, whereas the newer measurements are quasi-spherical and hexagonal plates. The WB-57F also measured very high water vapor contents with some instruments, up to 4 ppmv, and aerosols with mixed organics and sulfates. It is unknown whether these ambient conditions were present in the 1973 studies, and whether such conditions have an influence on particle shape and the development of the large particles. A companion paper (Jensen et al., 2008) presents crystal growth calculations that suggest that the high water vapor measurements are required to grow ice particles to the observed sizes of $100 \mu \mathrm{m}$ and larger.
\end{abstract}

\section{Introduction}

Subvisible cirrus (SVC) clouds appear mostly in the tropical tropopause layer (TTL) up to the tropopause (Wang et al., 1996; Beyerle et al., 1998; McFarquhar et al., 2000; Comstock et al., 2002; Clark, 2005), but have also been ob-

Correspondence to: R. P. Lawson

(plawson@specinc.com) served at midlatitudes (Sassen and Campbell, 2001; Immler and Schrems, 2002). The TTL is the region of the tropical atmosphere that lies between the top of the main cumulus outflow layer and the thermal tropopause (Folkins et al., 1999). This layer is a transition layer between dynamical control of the vertical mass flux by tropospheric convection, and by the stratospheric Brewer-Dobson circulation, and is crucial to understanding the dehydration of air entering the stratosphere.

Although the radiative forcing of optically thin SVC is relatively small, the clouds are generally thought to cover a large horizontal extent and some calculations suggest that they are radiatively significant. For example, McFarquhar et al. (2000) used a nadir-pointing Nd:YAG lidar on a Learjet and found that a spatially thin layer of cirrus, with base above $15 \mathrm{~km}$ and a mean thickness of $0.47 \mathrm{~km}$, was observed in the central Pacific tropics $29 \%$ of the time. Based on vertical profiles and a radiative transfer model, they calculate observed heating rates of up to $1.0 \mathrm{Kday}^{-1}$, principally in the infrared, and cloud radiative forcing of up to $1.2 \mathrm{~W} \mathrm{~m}^{-2}$. SVC clouds are occasionally observed above the tropopause at midlatitudes (Goldfarb et al., 2001) and in Polar Regions (Lelieveld et al., 1999; Kärcher and Solomon, 1999).

Supersaturation with respect to ice has been observed in the upper troposphere and lowermost stratosphere (Murphy et al., 1990; Gierens et al., 1999; Ovarlez et al., 2000; Jensen et al., 1999, 2001, 2005; Peter et al., 2006). Brewer (1949) showed that air entering the stratosphere is freeze dried as it crosses the cold tropical tropopause. Jensen et al. (1996) suggested that SVC can effectively freeze-dry air crossing the tropical tropopause to the observed lower stratospheric water vapor concentrations, which may significantly affect the Earth's radiation budget (Comstock et al., 2002).

SVC clouds were studied with the NASA WB-57F research aircraft in January- February 2006 during the Costa Rica - Aura Validation Experiment (CR-AVE http://cloud1. arc.nasa.gov/ave-costarica2). Figure 1 shows a photograph

Published by Copernicus Publications on behalf of the European Geosciences Union. 


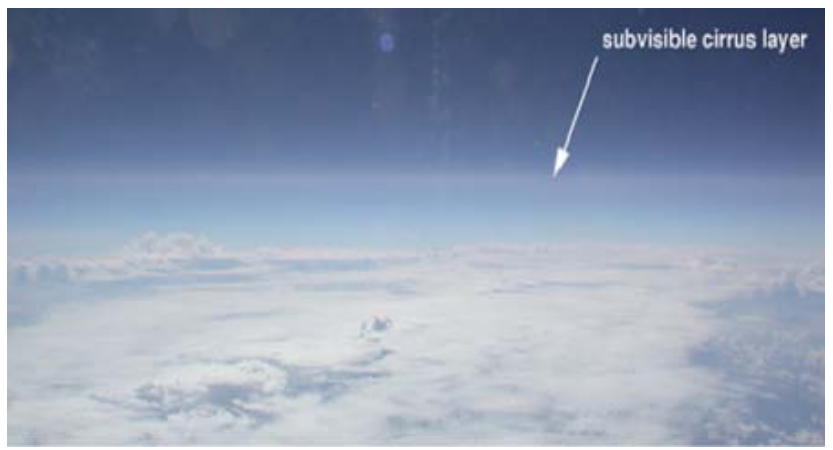

Fig. 1. Photograph of Subvisible Cirrus (SVC) layer taken from the cockpit of the NASA WB-57F during the transit flight from Houston, Texas for the Costa Rica Aura Validation Experiment (CRAVE). See acknowledgements for photo credit.

of an SVC layer taken from the cockpit of the WB-57F during the transit flight from Houston to San Jose, Costa Rica. While there have been several studies of SVC using airborne, satellite and ground-based lidar, there has been a relative dearth of in situ microphysical measurements. Heymsfield (1986) and McFarquhar et al. (2000) discuss measurements made by a WB-57F in a SVC cloud at $-84^{\circ} \mathrm{C}$ over the Marshall Islands on 17 December 1973. Based on an examination of replicator data, they concluded that particle sizes ranged from about 5 to $50 \mu \mathrm{m}$ and particle shapes were mostly columnar and trigonal plates, with some hexagonal plates. The only other microphysical measurements in SVC that we are aware of have been made with scattering probes, such as the forward scattering spectrometer probe (FSSP). For example, Thomas et al. (2002) found a modal peak in the size distribution between about 2 and $17 \mu \mathrm{m}$, and Peter et al. (2003) found a model peak of 10 to $12 \mu \mathrm{m}$, both studies used an FSSP-300 (Baumgardner et al., 1992), which measured particles from 0.4 to $23 \mu \mathrm{m}$ in size.

The microphysical measurements collected in SVC by the WB-57F research platform include, for the first time, digital images of particles from a cloud particle imager (CPI) probe (Lawson et al., 2001), a cloud and aerosol particle spectrometer (CAPS) probe (Baumgardner et al., 2001) and a new device, the 2D-S probe (Lawson et al., 2006). Data from the CPI, CAPS and 2D-S are analyzed from four WB-57F missions when all three instruments were functioning. Temperature, pressure and true airspeed measurements come from the WB-57F meteorological measurement system (Scott et al., 1990) and water vapor measurements are from the Harvard Integrated Cavity Output Spectroscopy (ICOS) instrument (Sayres, 2006). The data presented here represent approximately $1800 \mathrm{~km}$ of WB-57F flight in SVC during the CR-AVE project. The CPI recorded 8524 images and the 2D-S probe recorded over 100000 images of ice particles in SVC.

\section{Instrumentation and data}

A highlight of CR-AVE field campaign was the full complement of state-of-the art microphysical probes used to extensively investigate SVC. The combination of particle probes, CPI, 2D-S and CAPS, provided extensive overlap in particle size distributions and high-resolution (CPI) digital images of the particles in SVC. The CAPS probe was mounted on a pylon above the right wing and the CPI and 2D-S probes were mounted on individual pylons that hung below the right wing. Data for this paper were extracted from the CR-AVE archives. Before being placed in the archives, 2D-S data were averaged over $1 \mathrm{~s}$, CPI data were averaged over $10 \mathrm{~s}$ and CAPS data were averaged over $30 \mathrm{~s}$. In order to generate $1-\mathrm{Hz}$ CAPS data that could be combined with 2D-S data, each 30-s averaged CAPS value was repeated 30 times. Both 2D-S and CAPS data were then used to generate a combined particle size distribution (PSD) and derived parameters on a $1 \mathrm{~Hz}$ basis.

The subject of ice particles shattering on the inlets of particle probes has been recently discussed in the literature (Field et al., 2003; Korolev and Isaac, 2005; Field et al., 2006). Field et al. (2003) found that the minimum ice particle size that produced shattering on an FSSP was about $350 \mu \mathrm{m}$. Since ice particles did not exceed $165 \mu \mathrm{m}$ in this study, particle shattering on probe inlets is unlikely. To further ascertain that particle shattering was insignificant in our SVC data set, we examined 2D-S and CPI images and found no visual evidence of shattered particles, which can often be identified as particles that appear to have "burst". In addition, we eliminated closely-spaced 2D-S particles using the arrival time technique described in Field et al. (2006), and found no significant difference in particle concentration. This combination of tests leads us to the conclusion that particle shattering was not a factor in this SVC data set. The possibility of particle coincidence in the 2D-S data set was evaluated by visually examining the number of particles in each image strip. The results of this study showed that the contribution of particle coincidence was negligible.

The CAPS contains two particle probes, a cloud and aerosol spectrometer (CAS), which measures forward and backward scattered light to count and size particles from 0.5 to $50 \mu \mathrm{m}$, and a cloud imaging probe that images particles from 75 to $1600 \mu \mathrm{m}$ with $25 \mu \mathrm{m}$ pixels.

The CPI has $2.3 \mu \mathrm{m}$ pixels, which provides highresolution digital images of ice particles in SVC. The particle detection sample volume of the CPI is $0.7 \mathrm{~L} \mathrm{~s}^{-1}$ at $180 \mathrm{~m} \mathrm{~s}^{-1}$, which is a typical true airspeed of the WB-57F. Measurements of airspeed using a miniature pitot tube in the sample volume of a CPI installed on a Learjet showed that the airspeed equaled the ambient airspeed. The particle detection system in the CPI operates continuously and detects cloud particles with sizes $10 \mu \mathrm{m}$ and larger. While particle coincidence can occur when particle concentrations are high (e.g., $>10 \mathrm{~cm}^{-3}$ ), examination of the CPI data set showed 
no occurrences of particle coincidence in the relatively low particle concentrations found in SVC. The CPI sample volume is relatively small compared with optical array probes, which are preferred for measurements of the large end of the particle size distribution.

The $2 \mathrm{D}-\mathrm{S}$ is a new imaging probe that has true $10 \mu \mathrm{m}$ per pixel resolution at jet aircraft airspeeds, whereas the response of the older 2-D imaging probes is degraded with airspeed. At the true airspeed of the WB-57F at $55000 \mathrm{ft}$ ), the older 2$\mathrm{D}$ imaging probes do not detect particles with sizes less than 50 to $100 \mu \mathrm{m}$ (Lawson et al., 2006). Determination of the 2D-S sample volume is described in Lawson et al. (2006), and for particles $<100 \mu \mathrm{m}$ it is a function of effective depth of field $\left(\mathrm{DOF}_{\text {eff }}\right)$. The $\mathrm{DOF}_{\text {eff }}$ of the $2 \mathrm{D}-\mathrm{S}$ is determined from the relationship $\mathrm{DOF}_{\text {eff }}=$ plus and minus eight times particle radius squared divided by the wavelength of incident laser light. The sample volume is equal to true airspeed times $\mathrm{DOF}_{\text {eff }}$ (until the distance between the probe arms is reached), times $1.28 \mathrm{~mm}$. For example, for $50 \mu \mathrm{m}$ diameter spherical particles and an airspeed of $170 \mathrm{~m} \mathrm{~s}^{-1}$, the 2D-S sample volume is $2.8 \mathrm{~L} \mathrm{~s}^{-1}$, and for particles $>100 \mu \mathrm{m}$, the sample volume is $12 \mathrm{~L} \mathrm{~s}^{-1}$.

The true $10 \mu \mathrm{m}$ resolution of the $2 \mathrm{D}-\mathrm{S}$ facilitates resizing of out-of-focus images, which has otherwise been a source of error that has hampered older 2-D imaging probes (Korolev et al., 1998). Examples of 2D-S images in SVC and re-sizing using an algorithm developed by Korolev (2007) are shown in Fig. 2. The algorithm is based on theoretical diffraction and has been evaluated using images of glass beads in the laboratory. Results of the Korolev algorithm were compared with several sets of bead sizes, and it performed better on some bead sizes than it did on others. We examined the data sets to see if there were obvious physical explanations or systematic trends that would account for the discrepancies and found none. Later in this paper (Fig. 9) we show results of a PSD that has been resized using the Korolev (2007) algorithm compared with a PSD computed using only in-focus 2D-S images.

Water vapor was measured with multiple instruments on the WB-57F during the CRAVE flights. The Harvard water vapor instrument photodissociates $\mathrm{H}_{2} \mathrm{O}$ molecules with $121.6 \mathrm{~nm}($ Lyman- $\alpha)$ radiation and detects the resulting $\mathrm{OH}$ photofragment fluorescence at $315 \mathrm{~nm}$ (Weinstock et al., 1994). The Harvard ICOS instrument uses a mid-infrared quantum cascade laser at $1484 \mathrm{~cm}^{-1}$ to obtain measurements of $\mathrm{H}_{2} \mathrm{O}$, as well water vapor isotopes, with an effective path length of nearly $4 \mathrm{~km}$ (Sayres, 2006). The Jet Propulsion Laboratory Laser Hygrometer (JLH) is a tunable-diode laser focused that operates by harmonic wavelength modulation spectroscopy (May 1998). For over 50 years measurements of water vapor concentration in the TTL have been conducted using balloon-borne instrumentation, typically frostpoint chilled mirrors (Oltmans et al., 2000). A long-standing discrepancy has persisted between the frostpoint $\mathrm{H}_{2} \mathrm{O}$ measurements and aircraft-borne $\mathrm{H}_{2} \mathrm{O}$ measurements made using

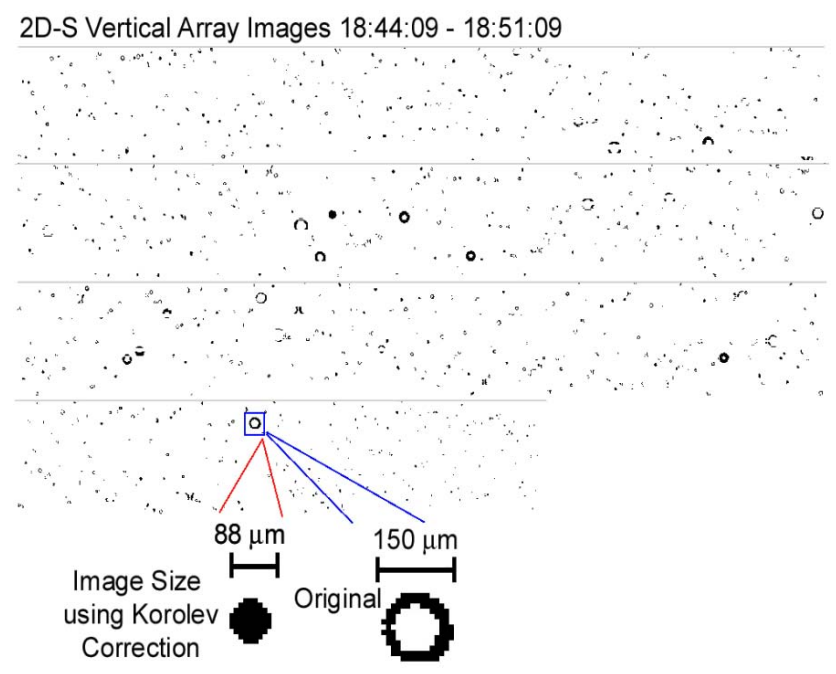

Fig. 2. 2D-S particle images from the vertical (V) channel of the $2 \mathrm{D}-\mathrm{S}$ probe and an example of size correction of a donut image using the Korolev (2007) resizing scheme.

a variety of techniques. This discrepancy was particularly glaring under the very dry tropopause conditions sampled during CR-AVE, with the frostpoint and JLH measurements typically reporting 1-2 ppmv whereas the ICOS and Harvard Water Vapor instruments report 3-4 ppmv. This discrepancy in water vapor measurements is germane to this paper, because calculations shown in Jensen et al. (2008) suggest that water vapor limits the maximum size to which ice particles can grow before they fall out of the upper region of the TTL.

\section{Characteristics of subvisible cirrus}

\subsection{Spatial and vertical extent}

Figure 3 shows the WB-57F flight track on the transit flight (TF 1) to San Jose, Costa Rica on 14 January 2006, and flight tracks for five research flights: RF 1 (17 January 2006), RF 5 (25 January 2006), RF 8 (1 February 2006), RF 9 (2 February 2006) and RF 11 (7 February 2006). These are flights when there were CPI data available. CPI data were used to identify regions when the WB-57F was in SVC, because out of all the particle probes, it had the lowest percentage of down time and was the most reliable indicator of SVC. Note that, as described in Section 2, the CPI particle detection system operates continuously and is sensitive to particles $10 \mu \mathrm{m}$ and larger. CPI data were also used to determine the shape of ice particles, because of its high-resolution imagery. Both CAPS and 2D-S data were available for TF 1, RF 5, RF 8 and RF 9, and data from these missions were used to compute the mean PSD's and average bulk parameters computed in SVC. Also shown in Fig. 3 are vertical profiles of the transit flight and research flights where the CPI observed SVC. 


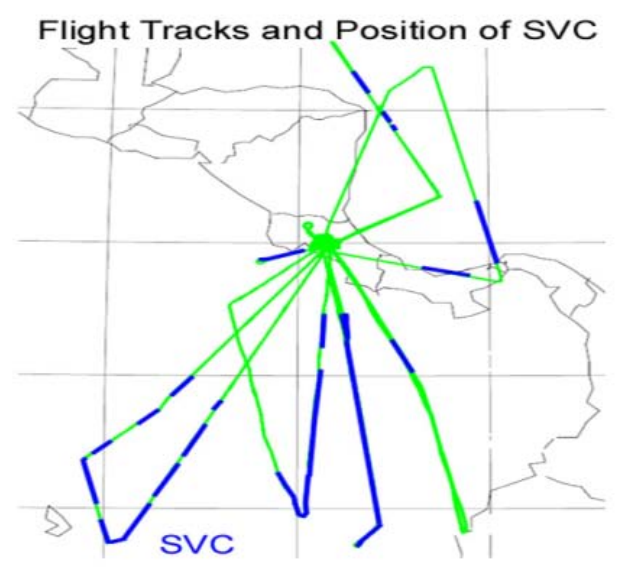

Flight Profiles of SVC

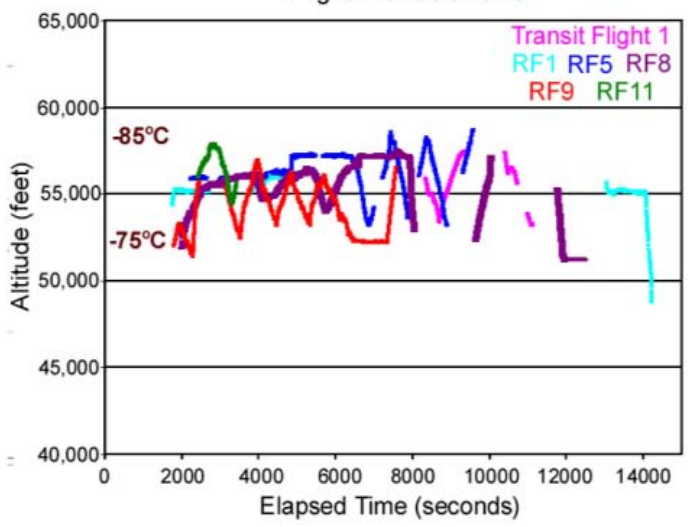

Fig. 3. (Top) WB-57F flight tracks during CR-AVE showing (in blue) regions where SVC was encountered and (Bottom) vertical profile showing location of SVC. The color code in the lower panel corresponds with the research flight (RF) number shown in the legend.

The data in Fig. 3 show that SVC was frequently observed and that it was consistently found between about $53000 \mathrm{ft}$ $(16.2 \mathrm{~km})$ and $58000 \mathrm{ft}(17.7 \mathrm{~km})$ m.s.l., which corresponds to a temperature range from about -75 to $-85^{\circ} \mathrm{C}$.

As suggested in Fig. 3, the WB-57F was generally in and out of SVC clouds during its mission profile, and sometimes porpoised from the top to the bottom of the cloud layer. Candidate regions of SVC were selected when the CPI particle concentration was $>0.1 \mathrm{~L}^{-1}$ for $>1 \mathrm{~km}$. Once these general regions of SVC were selected using CPI data, the general regions were further subdivided to avoid averaging regions of clear air with SVC cloud. This was accomplished by dividing the general SVC regions into flight legs that were chosen when the average $2 \mathrm{D}-\mathrm{S}$ particle concentration was $>5 \mathrm{~L}^{-1}$ for $5-\mathrm{km}$ or greater without containing a continuous period of clear air $\left(2 \mathrm{D}-\mathrm{S}\right.$ concentration $\left.<0.01 \mathrm{~L}^{-1}\right)$ that was $1-\mathrm{km}$ or greater. This resulted in 19 flight legs that were about 25 to $200 \mathrm{~km}$ in length, with one very long leg that extended for $2400 \mathrm{~km}$. Figure 4 shows an example of flight legs that were used for making PSD's from a time series of 2D-S particle

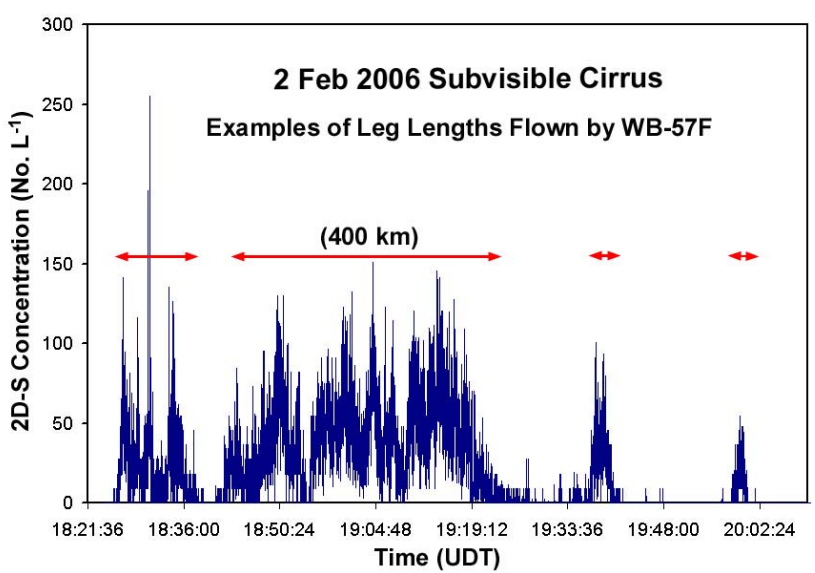

Fig. 4. Example of a time series of WB-57F 2D-S total particle concentration in SVC showing 4 of the 19 "legs" (red arrows) used in the analyses in this paper. Legs were selected using objective criteria explained in the text.

concentration during a portion of the mission on 2 February 2006.

\subsection{Particle habits}

Figure 5 shows examples of CPI images in SVC that have been sorted into particles $<65 \mu \mathrm{m}$ and particles $\geq 65 \mu \mathrm{m}$ in maximum dimension. The $65 \mu \mathrm{m}$ dimension was chosen because visual inspection showed that the shape of the CPI images typically changed at about this size. Images $<65 \mu \mathrm{m}$ appear to be mostly quasi-spherical and there is little light transmission through the images. Images $\geq 65 \mu \mathrm{m}$ start to appear disk shaped, with distinctive edges that are not apparent in the smaller spheroidal images. Also, several of the images $\geq 65 \mu \mathrm{m}$ start to take on a plate-like shape. This can be seen more clearly in panel a) in Fig. 6, which shows expanded views of several of the hexagonal particles. Panel b) in Fig. 6 shows irregular ice particles that appear to have distinctive edges on their basal faces. Panel c) in Fig. 6 shows examples of CPI images of glass beads taken in the laboratory, shown here for the sake of comparison. Several of 2D-S images of ice particles observed in SVC $\geq 100 \mu \mathrm{m}$ are shown in the companion paper by Jensen et al. (2008).

The CPI images in Figs. 5 and 6 are in sharp contrast to the only other known images of ice particles in the TTL, which were collected on 17 December 1973 using a replicator installed on a WB-57F research aircraft flying between 16.2 and $16.7 \mathrm{~km}\left(-83^{\circ} \mathrm{C}\right.$ to $\left.-84^{\circ} \mathrm{C}\right)$ over the Marshall Islands (Heymsfield, 1986; McFarquhar et al., 2000). Heymsfield (1986) shows a few images where the shapes of the ice particles are mostly columnar and trigonal (with some plates), ranging in size from about 5 to $50 \mu \mathrm{m}$. The differences in particle size and shapes observed in the 1973 Kwajalein and 2006 CR-AVE field campaigns cannot be explained, but 

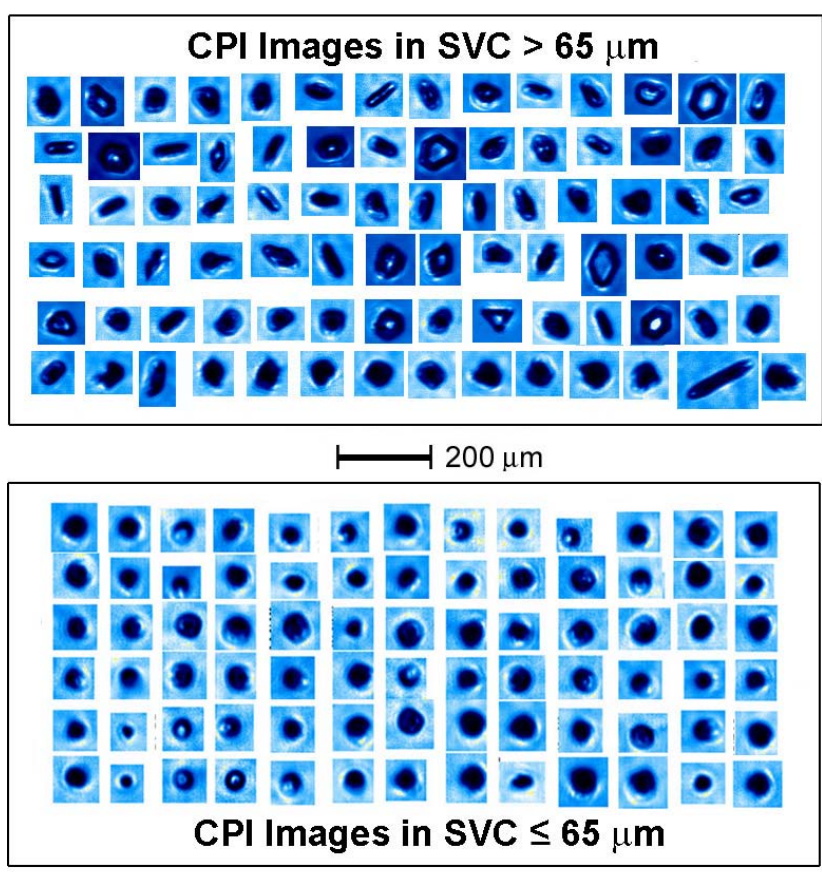

Fig. 5. Examples of CPI images in subvisible cirrus (SVC) of (top) ice particles $>65 \mu \mathrm{m}$ and (bottom) $\leq 65 \mu \mathrm{m}$.

these differences could potentially have a significant impact on cloud radiative forcing (Stephens et al., 1990; Macke et al., 1998; Wendisch et al., 2007). The effects of shape on particle growth, fall velocity and lifetime are examined in the particle growth model presented in Jensen et al. (2008).

In order to be certain that the CPI images have disk-like edges that are not an optical aberration, we captured images of $80 \mu \mathrm{m}$ glass beads using the CR-AVE CPI in the laboratory and examined images on all locations in the CPI viewing volume. A few images of glass beads that come the closest to producing what appears to be an edge are also shown in Fig. 6. It is apparent from comparing the ice particle images in SVC with the images of spherical glass beads that, most likely, the edges are not an optical aberration of a (glass) sphere. Also, we could not find any evidence of disk-like edges upon examining quasi-spherical images of 50 to $100 \mu \mathrm{m}$ ice particles in anvil cirrus observed during CRAVE, further suggesting that the disk-like and plate-like SVC ice particles are real.

A geometric analysis of a CPI image (Appendix A) suggests that the aspect ratio (basal to prism faces) is on the order of $6: 1$. However, it is not possible from this crystal image to determine if the aspect ratio is actually larger than $6: 1$, because of the amount of blur in the image due to diffraction and optical aberrations. For example, the CPI image in the lower left frame of the plate-like images in Fig. 6 appears to have an aspect ratio of $6: 1$, assuming it is a plate being viewed orthogonal to the prism face (and 1:6 if it is actually

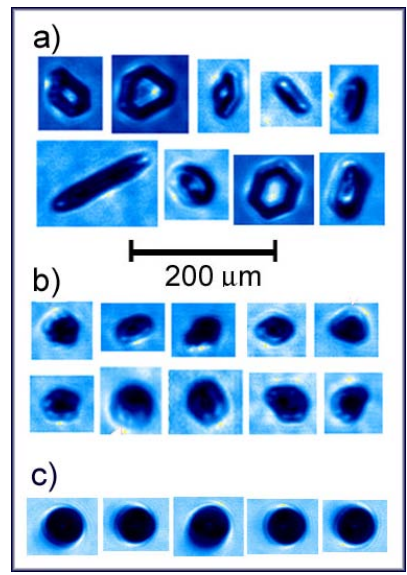

Fig. 6. Examples of CPI images in (a) SVC that show edges (prism faces) of the larger plate-like and (b) irregular crystals, and (c) examples of images of glass beads taken in the laboratory for the sake of comparison.

a column). However, if it is a tilted plate, it will actually have a slightly larger aspect ratio. Also, if the prism face is significantly blurred due to diffraction and optical aberrations, the dimension of the prism face will be artificially lengthened, and the aspect ratio will be erroneously decreased.

The aspect ratio of these larger crystals is germane to the crystal growth calculations and relative humidity measurements presented in a companion paper (Jensen et al., 2008). In this paper we choose not to offer an estimate of the largest likely aspect ratio of these crystals, since any estimate will contain some degree of ambiguity and will be a subjective analysis of thickness of the image edge.

Figure 7 shows histograms of particle habits classified by a trained analyst for all of the CPI images collected in SVC and from only those images $\geq 65 \mu \mathrm{m}$. The histograms comparison between particles $<65 \mu \mathrm{m}$ and those $\geq 65 \mu \mathrm{m}$ shows considerably fewer quasi-spheroids in the larger particle histogram and a significant increase in plate-like and edged irregulars (also note that the "columns" may be plates viewed on edge).

The CR-AVE data in SVC observed near Costa Rica contained a few particles that were significantly larger (by about $100 \mu \mathrm{m})$ and markedly different crystal habits than the observations reported by Heymsfield (1986) over the Marshall Islands. The lack of trigonal ice in the CR-AVE SVC data set is curious. The replicator images shown in Heymsfield (1986) are clearly trigonal. The CPI images are not quite as sharp as the replicator images, but once particles are larger than about $30 \mu \mathrm{m}$, trigonal shapes will be clearly identifiable, if they exist. Thus, the differences in particle habits between the Heymsfield (1986) case and the CR-AVE data set cannot be attributed to instrumental effects. The data set collected in 1973 is 33 years previous to the CR-AVE data, and the possibility exists that differences in the moisture field 


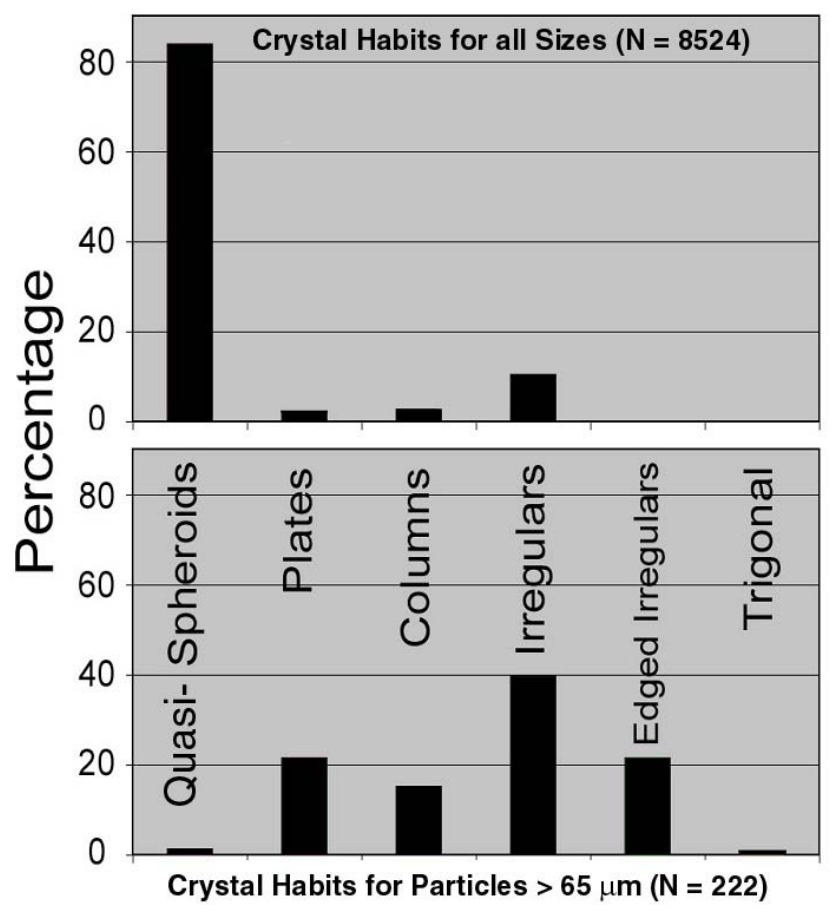

Fig. 7. Comparison of crystal habits for (top) all crystals and (bottom) crystals $>65 \mu \mathrm{m}$ in SVC. Particle habits were classified manually based on CPI images.

and atmospheric chemistry have changed over the past three decades; however, moisture and chemistry instrumentation was not installed on the WB-57F for the 1973 flights.

\subsection{Particle size distributions (PSD's) and bulk properties}

Figure 8 shows PSD's as a function of number, area and mass, based on $\sim 1800 \mathrm{~km}$ of WB-57F flight in SVC during the four missions discussed in Sect. 3.1. Compared with the 2D-S mean PSD, there is a sharp drop in the CAPS (CAS) mean concentration at $5 \mu \mathrm{m}$. The CAS data applies Mie scattering theory to size particles, and implicit in Mie theory is the assumption that the particles are perfect spheres. Since the CAS is sizing ice that is not perfectly spherical, the sizing uncertainty is unknown. Also, it uses three stages of gain amplifiers, and the transition from one of the stages to another occurs at $5 \mu \mathrm{m}$ (where the dip starts in the CAPS PSD). We chose to use the 2D-S PSD in the size region from 10 to $30 \mu \mathrm{m}$ region and interpolate between CAS and 2D$\mathrm{S}$ between 5 and $10 \mu \mathrm{m}$. Figure 8 shows that, compared with the 2D-S, the CAPS indicates a higher concentration in the size range from 50 to $150 \mu \mathrm{m}$, and that it recorded particles as large as $225 \mu \mathrm{m}$, while the largest 2D-S particle was $165 \mu \mathrm{m}$. Both the CAPS and 2D-S data were processed using image-resizing schemes based on Korolev (2007). A check on 2D-S resizing was accomplished by comparing a PSD of infocus images with resized images using the Korolev (2007) technique. However, there were only 18 2D-S

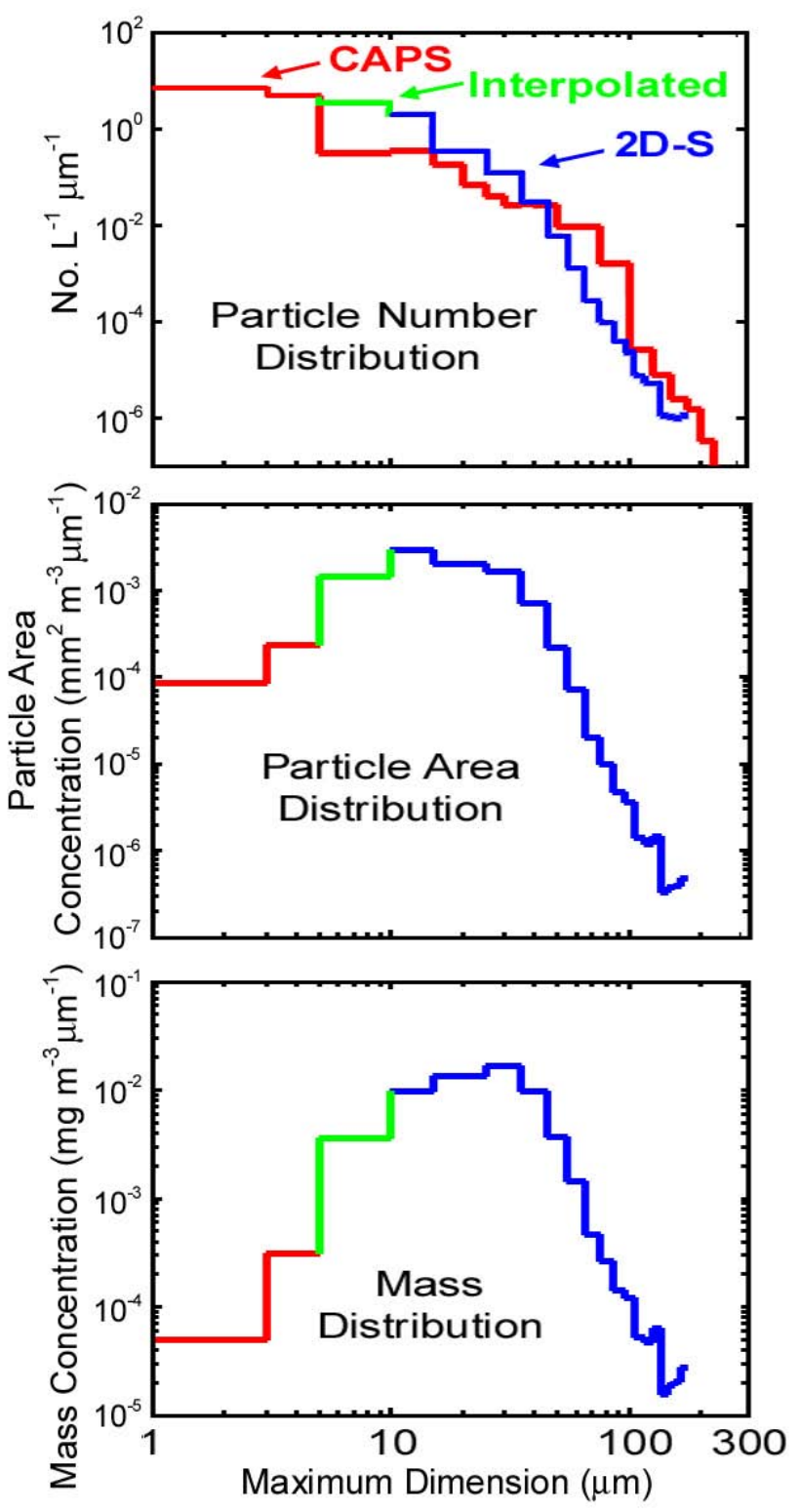

Fig. 8. PSD's of (top) number concentration, (middle) area and (bottom) mass based on $\sim 1800 \mathrm{~km}$ of WB-57F $2 \mathrm{D}-\mathrm{S}$ and CAPS measurements collected in SVC. Green trace is interpolated between $5 \mu \mathrm{m}$ CAS and $10 \mu \mathrm{m}$ 2D-S size bins.

particles $>100 \mu \mathrm{m}$ in the CR-AVE data set and only a few of these were in focus, so a comparison using the CR-AVE data set would not produce adequate statistics. Instead, a very large data set (137222 total 2D-S images with $5601 \mathrm{im}$ ages $>100 \mu \mathrm{m}$ ) collected in drizzle during the 2005 Rain in Cumulus over the Ocean (RICO) experiment was processed. The RICO drizzle images appear very similar in shape to the quasi-spherical SVC images.

Figure 9 shows the results of comparing PSD's using only infocus 2D-S images with all images processed using standard 2-D technique (i.e., the maximum image dimension 
Table 1. Bulk properties of SVC observed by the WB-57F on 4 missions. Means and standard deviations $(\sigma)$ are an average of 8738 1-Hz averaged measurements collected by WB-57F from 19 legs in SVC. Max and Min are leg-averaged maximums and minimums of the 19 legs.

\begin{tabular}{|c|c|c|c|c|}
\hline & Mean & $\sigma$ & Max & Min \\
\hline $\begin{array}{l}\text { Particle Concentration (No. } \\
\mathrm{L}^{-1} \text { ) }\end{array}$ & 66.0 & 30.8 & 188.8 & 22.5 \\
\hline $\begin{array}{l}\text { Particle Concentration } \\
>65 \mu \mathrm{m}\left(\text { No. } \mathrm{L}^{-1}\right)\end{array}$ & 0.004 & 0.017 & 0.08 & 0.00 \\
\hline $\mathrm{R}_{\mathrm{eff}}(\mu \mathrm{m})$ & 8.82 & 2.44 & 16.7 & 5.51 \\
\hline Extinction $\left(\mathrm{km}^{-1}\right)$ & 0.009 & 0.011 & 0.063 & 0.002 \\
\hline $\operatorname{IWC}\left(\mathrm{mg} \mathrm{m}^{-3}\right)$ & 0.055 & 0.098 & 0.503 & 0.012 \\
\hline
\end{tabular}

across the array) and images resized using the Korolev (2007) scheme. Appendix B discusses sizing errors using only infocus images, which will usually result in a PSD with the smallest particle sizes. In Fig. 8, using infocus images does produce the smallest PSD, while the PSD produced based on the Korolev (2007) algorithm falls between the infocus and standard processing PSD. Based on the comparisons shown in Figs. 8 and 9, it appears that the 2D-S produces more reliable information in from 10 to $165 \mu \mathrm{m}$ (the largest 2D-S particle size observed), and therefore the 2D-S data are used in that size range.

McFarquhar et al. (2000) show data in SVC from a Particle Measuring Systems (PMS) axially scattering spectrometer probe (ASSP) with a size range from 2 to $30 \mu \mathrm{m}$, and PMS 1-D probe that is intended to size particles from 20 to $300 \mu \mathrm{m}$. However, recent studies (Lawson et al., 2006) suggest that the slow time response of the 1-D probe, which uses a diode array and front-end amplifier comparable to the 2D$\mathrm{C}$, limit its response to particles larger than about $100 \mu \mathrm{m}$ at the Learjet airspeeds used in that study. The PSD shown in Fig. 1 in McFarquhar et al. (2000) extends from 2 to $15 \mu \mathrm{m}$, with some 1-D probe activity in the 20 to $50 \mu \mathrm{m}$ size range. However, these are likely to be much larger particles that are undersized due to limitations imposed by the time response of the 1-D probe. Interestingly, the ASSP PSD that extends from 2 to $15 \mu \mathrm{m}$ shown by McFarquhar et al. (2000) is similar to the composite CR-AVE PSD shown in Fig. 8, (but it is not similar to the CAS PSD alone). Figure 8 also shows average composite PSD's as a function of particle area and particle mass. The particle area size distribution strongly influences optical cloud properties, such as extinction and optical depth. The particle mass size distribution has an impact on ice water content (IWC) and ice water path.

The average bulk properties shown in Table 1 were derived by computing a time-weighted average from each of the 19 WB-57F legs in SVC (i.e., the sum of the number of $1-\mathrm{Hz}$ data points in each leg times the leg average divided by total number of data points in all legs). Extinction is computed from 2D-S projected particle image area and the geometrics optics assumption. IWC is computed assuming that the par-

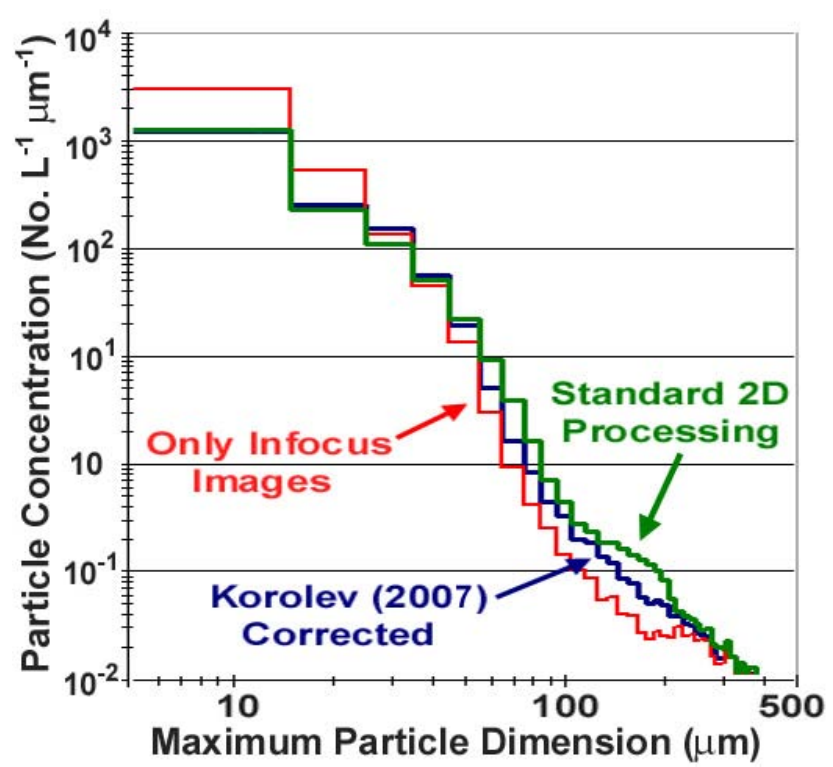

Fig. 9. Comparison of PSD's from drizzle observed in the RICO project using (green) standard 2-D processing technique, (red) only in-focus 2D-S images and (blue) images that have been resized based on the Korolev (2007) algorithm.

ticles are spherical and the density of ice is $0.918 \mathrm{~g} \mathrm{~cm}^{-3}$. Effective radius is computed by dividing particle mass by particle projected area. Particle projected area is simply the number of shaded pixels and particle mass is computed using the particle area-to-mass relationship found in Baker and Lawson (2006).

The average particle concentration $\left(66 \mathrm{~L}^{-1}\right)$, extinction coefficient $\left(0.009 \mathrm{~km}^{-1}\right)$, effective radius $(8.82 \mu \mathrm{m})$ and IWC $\left(0.055 \mathrm{mg} \mathrm{m}^{-3}\right)$ are very close to values derived from graphs shown in McFarquhar et al. (2000). McFarquhar et al. measured IWC values from 0.001 to $0.1 \mathrm{mg} \mathrm{m}^{-3}$, and show an average value of about 0.05 during a descent through SVC in their Fig. 2. They measured a value of about $11 \mu \mathrm{m}$ for effective radius on the same flight. Based on cloud lidar system (CLS) measurements from the NASA ER-2 research aircraft, 


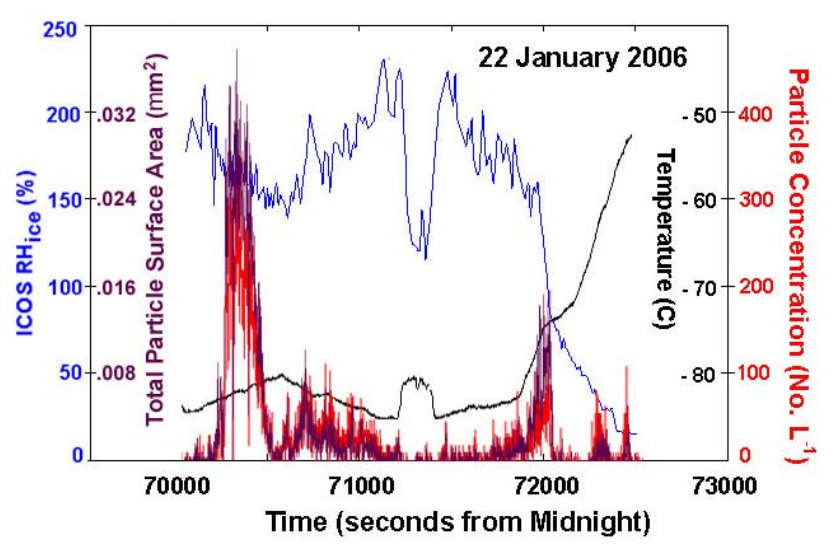

Fig. 10. Example of time series of 2D-S particle concentration, temperature and ICOS $\mathrm{RH}_{\text {ice }}$.

McFarquhar et al. show a mean value of $\tau=0.045$ for optical depth, based on an average CLS cloud thickness measurement of $0.47 \mathrm{~km}$. Using WB-57F porpoising maneuvers to estimate SVC thickness in CR-AVE yields a range from about 0.5 to $1 \mathrm{~km}$, which translates to an optical depth of 0.045 to 0.09 .

Jensen and Pfister (2004) simulated formation of TTL cirrus along trajectory curtains throughout the tropics using a detailed cloud model. Temperature profiles in the model were taken from meteorological analyses with wave-driven perturbations superimposed. The model tracks the growth and sedimentation of thousands of individual ice crystals within each column of air (see Jensen and Pfister, 2004, for details). The simulated mean ice concentration $\left(5 \mathrm{~L}^{-1}\right)$ and effective radius $(7.3 \mu \mathrm{m})$ agree remarkably well with CRAVE measurements (Table 1). Note that if we do not include gravity wave-driven temperature perturbations in the model, then the simulated ice concentrations $\left(18 \mathrm{~L}^{-1}\right)$ are much lower than the observed values $\left(66 \mathrm{~L}^{-1}\right)$.

\subsection{Large particles}

The ice particles observed in SVC during CR-AVE extend to larger sizes than previously reported by Heymsfield (1986), McFarquhar et al. (2000) and Thomas et al. (2002). There were 35 measurements out of a total of $87381-\mathrm{Hz} 2 \mathrm{D}-\mathrm{S}$ measurements that contained ice particles $\geq 100 \mu \mathrm{m}$, and the maximum infocus particle size observed is $165 \mu \mathrm{m}$. The maximum length of the largest CPI image is $151 \mu \mathrm{m}$. However, the previous investigations were incapable of properly measuring these larger particles (with the possible exception of the replicator used by Heymsfield, 1986). McFarquhar et al. do mention that collateral studies in 1973 with the Aeromet Learjet near Kwajalein in the Marshall Islands using PMS probes report ice particles up to $140 \mu \mathrm{m}$ in thin cirrus between 14 and $15 \mathrm{~km}$ (45 000 and $49000 \mathrm{ft}$ ), but these clouds are much lower than the SVC that exists at the base of the tropopause.
While the larger particles occasionally observed during CR-AVE do not have a significant impact on bulk microphysical properties, they do raise the question of how such relatively large particles can exist near the tropopause. Jensen et al. (2008) use back trajectory analysis to show that the crystals did not originate in convection. The large-scale vertical ascent velocity in the TTL has been estimated to be low, on the order of a cm s${ }^{-1}$ or less (Heymsfield, 1986). Growthsedimentation calculations suggest the crystals cannot grow to these sizes before falling out of the supersaturated TTL layer unless the ice supersaturations are on the order of $100 \%$ or more (Jensen et al., 2008). This gives rise to discussions of discrepancies in results from different water vapor measurement technologies that are used in the TTL.

Balloon-borne measurements of frostpoint temperature in the TTL began in 1949 (Barrett et al., 1950) and have been considered the only reliable technology until the recent development of tunable diode and quantum cavity lasers (May, 1998; Sayres, 2006) ${ }^{1}$. The growth of large ice particles and how this process is affected by measurements of water vapor in the TTL is the subject of a companion paper (Jensen et al., 2008). In this paper we consider some relationships between ice particle size and water vapor measurements from the ICOS.

Figure 10 shows a time series with $\mathrm{RH}_{\text {ice }}$, temperature, total particle concentration and total particle surface area on 22 January 2006 where appreciable ice is only found at $\mathrm{RH}_{\text {ice }}>150 \%$, and even higher values of $\mathrm{RH}_{\text {ice }}$ correspond with the lowest values of both total particle concentration and total particle surface area. Extensive measurements of water vapor in mid-latitude cirrus at temperatures $<-40^{\circ} \mathrm{C}$ in both the Northern and Southern Hemispheres show that more than $75 \%$ of the measurements in both hemispheres range between $90 \%<\mathrm{RH}_{\text {ice }}<110 \%$ (Ovarlez et al., 2002). The authors suggest that the predominance of $\mathrm{RH}_{\mathrm{ice}} \approx 100 \%$ measurements is a result of an equilibrium condition in these cirrus clouds. In contrast, Fig. 11 shows that more than half of the CR-AVE ICOS $\mathrm{RH}_{\text {ice }}$ measurements in SVC exceeded 160\%, which Koop et al. (2000) suggests is the value at which homogeneous nucleation occurs. Murphy et al. (2006) and Murphy (2007, personal communication) report that TTL aerosols are composed mainly of sulfates mixed with organics. The obvious differences between the mid-latitude cirrus data and our observations are the colder temperatures and aerosol chemistry in the upper TTL. However, there are no obvious physical mechanisms that explain the observed SVC particle sizes and shapes.

\footnotetext{
${ }^{1}$ A workshop that focused on discrepancies between balloonborne frostpoint and laser-based measurements of water vapor and other aspects of the TTL was convened by NASA in November 2006.
} 


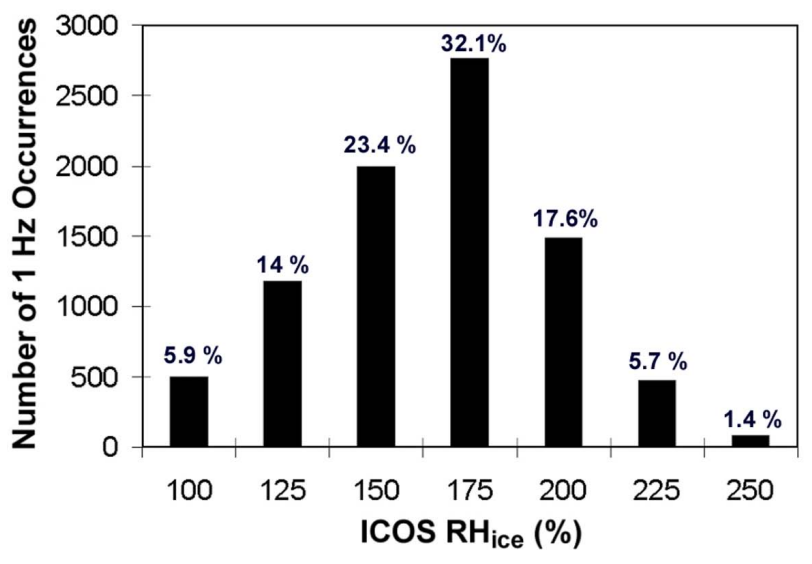

Fig. 11. Histogram of 8560 ICOS $\mathrm{RH}_{\text {ice }}$ measurements in SVC when $\mathrm{RH}_{\text {ice }}$ exceeded $100 \%$.

\section{Summary}

During the 2006 CR-AVE project staged from Costa Rica, the NASA WB-57F often observed SVC in the temperature range from $-75^{\circ}$ to $-85^{\circ} \mathrm{C}$ within about $1 \mathrm{~km}$ of the tropopause between about 0 and $10^{\circ} \mathrm{N}$ Latitude. The average ice particle number concentration $\left(66 \mathrm{~L}^{-1}\right)$, extinction coefficient $\left(0.009 \mathrm{~km}^{-1}\right)$, ice water content $\left(0.055 \mathrm{mg} \mathrm{m}^{-3}\right)$, effective radius $(8.82 \mu \mathrm{m})$ and optical depth $(0.045$ to 0.09$)$ are similar to values computed from in situ measurements over the Marshall Islands by McFarquhar et al. (2000). However, CPI images of the ice particles observed in CR-AVE were markedly different, with $84 \%$ of the particles being quasispherical, and particles larger than about $65 \mu \mathrm{m}$ exhibiting disk-shaped and hexplate characteristics. In comparison, McFarquhar et al. (2000) report a 50\% mixture of columns and trigonal plates (based on Heymsfield, 1986, replicator data collected in 1973).

Also, the size of CR-AVE particles extended to $165 \mu \mathrm{m}$, while McFarquhar et al. (2000) found the largest particles in TTL SVC were $50 \mu \mathrm{m}$, in both the $1973 \mathrm{WB}-57 \mathrm{~F}$ study and an investigation in 1993 using a Learjet. While the CR-AVE measurements covered a large region around Costa Rica, neither the CR-AVE measurements nor the 1973 measurements near Kwajalein should be considered representative of SVC in general, since SVC occurs in several places around the globe and more data need to be collected.

The apparent difference in particle size between the Heymsfield (1986) data and recent CR-AVE measurements may be due to limitations of the PMS 1-D probe used in the earlier studies (Lawson et al., 2006). However, the difference in the shape of the particles appears to be real and is not readily explained. One possible difference is that very high relative humidity (in excess of 200\%) observed by the WB-57F during CR-AVE was not present in the 1973 case reported by Heymsfield (1986). Based on a numerical model, Jensen

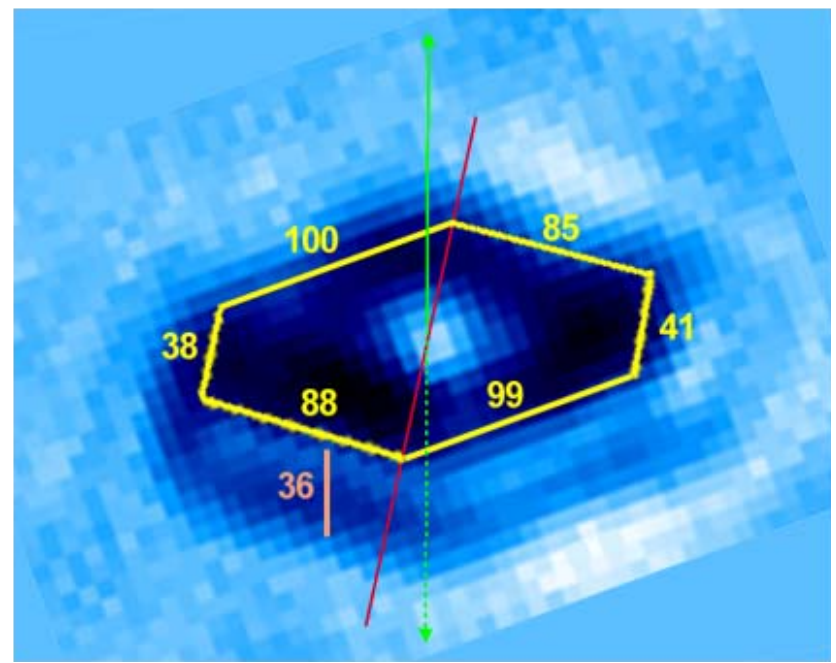

Fig. A1. Zoomed view of CPI image of ice particle shown in Fig. 6. See text for explanation of lines and numbers.

et al. (2008) show that, for crystals with aspect ratios of 6:1 or less, 3 to 4 ppmv water vapor (i.e., about $200 \%$ to $250 \%$ $\mathrm{RH}_{\text {ice }}$ at $-85^{\circ} \mathrm{C}$ ) is necessary to grow ice particles with sizes on the order of $100 \mu \mathrm{m}$ within about $500 \mathrm{~m}$ of the tropopause. Also, chemistry measurements near Costa Rica in 2004 and during CR-AVE suggest that the TTL is composed mainly of sulfates mixed with organics (Murphy et al., 2006; Murphy, personal communication, 2007). Nucleation and growth of ice particles at $-85^{\circ} \mathrm{C}$ in the presence of sulfates mixed with organics and very high relative humidity are mechanisms that need to be investigated more thoroughly.

\section{Appendix A}

\section{Calculation of particle aspect ratio from CPI images}

Two-dimensional particle imagery (e.g., CPI images) limits the amount of three-dimensional information retrievable from any given image. However, the aspect ratio (an essentially two-dimensional quantity) can be estimated from some CPI images that view the crystal from a fortuitous angle. Estimates of particle aspect ratio (i.e., ratio of dimensions of basal to prism faces) based on a CPI image from the CR-AVE data set that reveals three-dimensional qualities are discussed in this Appendix.

Figure A1 shows a magnified and rotated view of the crystal third from the left in the top row of images in Fig. 6. The crystal appears to be a hexagonal plate viewed from such an angle that a basal face and at least two prism faces are seen. Assuming hexagonal symmetry an estimate of the view direction and thus of the aspect ratio can be made. Drawn over the image in Fig. A1 are yellow lines approximating the locations of the six edges of the basal face. The relative (i.e. 
Table B1. $D_{m}$ is the observed size along the array. $D_{o}$ is the smallest possible image size (i.e., the actual particle when in focus) and $D_{m}+10$ is the largest possible image size given errors discussed in the text.

\begin{tabular}{lllllll}
\hline$D \mathrm{~m}$ & $D_{m}-10$ & $D_{s} /\left(D_{m}-10\right)$ & $\mathrm{Z}_{d}$ & $\left(D_{m}-10\right) / D_{o}$ & $D_{o}$ & $D_{m}+10$ \\
\hline 50.000 & 40.000 & 0.375 & 2.420 & 1.166 & 34.299 & 60.000 \\
75.000 & 65.000 & 0.231 & 1.810 & 1.412 & 46.030 & 85.000 \\
100.000 & 90.000 & 0.167 & 1.058 & 1.142 & 78.800 & 110.000 \\
125.000 & 115.000 & 0.130 & 0.900 & 1.238 & 92.894 & 135.000 \\
150.000 & 140.000 & 0.107 & 0.709 & 1.191 & 117.570 & 160.000 \\
175.000 & 165.000 & 0.091 & 0.580 & 1.143 & 144.403 & 185.000 \\
\hline
\end{tabular}

arbitrary units) lengths of these lines are indicated in yellow as well. Opposite edges of the basal face are similar in length as expected by symmetry.

Let $A$ represent the average length of the shortest pair of basal edges (i.e. 39.5), $B$ represent the average of the midlength pair (i.e. 86.5), and $C$ the average of the longest pair of edges (i.e. 99.5). Let $\Phi$ represent the angle between the normal to the crystal's basal face (i.e. the c-axis) and the view direction and $\theta$ the angle between the red line in the plane of the basal face and the projection of the viewing direction onto the same plane. Let $L$ represent the true length of the edges (in the same arbitrary units). Basic trigonometry assuming a hexagonal plate yields:

$A^{2} / L^{2}=\cos ^{2}(\Phi) \cos ^{2}(\Theta)+\sin ^{2}(\Theta)$

$B^{2} / L^{2}=\cos ^{2}(\Phi) \cos ^{2}(60-\Theta)+\sin ^{2}(60-\Theta)$

$C^{2} / L^{2}=\cos ^{2}(\Phi) \cos ^{2}(60+\Theta)+\sin ^{2}(60+\Theta)$

Solving these equations for the values of $A, B$, and $C$ specified, yields: $L \approx 106, \theta \approx 8^{\circ}$, and $\Phi \approx 70^{\circ}$.

The pink line represents the thickness of the plate from the view angle. It's length (36), in the same arbitrary units, must be divided by $\sin (\Phi)$ to obtain an estimate of the actual thickness $(T H)$. The aspect ratio is then the ratio of $2 L / T H$ or about 5.5:1. The largest uncertainty is in the choice of the thickness (pink line). Figure 6 shows that the CPI optics can blur edges making them look thicker than they are. If this is causing an exaggeration of the thickness then we may be underestimating the aspect ratio. Therefore, we conclude that the aspect ratio of this crystal is on the order of $6: 1$.

\section{Appendix B}

\section{Uncertainty in the size of ice particle images}

\section{B1 2D-S Images}

For 2D-S images that appear to be in focus (i.e., all pixels are black; there are no white pixels in the center), there are three sources of uncertainty. Each are considered in turn below:
1. Uncertainty due to the effective pixel size of the photo diodes in the sample volume. For the 2D-S the effective pixel size is $10 \mu \mathrm{m}$.

2. Uncertainty in the calibration of effective pixel size due to uncertainty in the laboratory calibration of glass beads used to determine effective pixel size. Based on discussion with the bead manufacturer, Duke Scientific, this uncertainty is about $5 \%$ of the image size.

3. An image can be somewhat out of focus, thus enlarged, and still appear in- focus (all image pixels are black; no white pixels in the center). Using the tables found in Korolev (2007), the result depends on the size of the image rather than being a fixed value, or fixed percentage as discussed above in items 1 and 2. Estimates of the maximum error are shown as function of image size in Table B1, based on the following discussion.

Table B1 shows calculations of actual image sizes $\left(D_{o}\right)$ for six apparent image sizes $\left(D_{m}=50,75,100,125,150\right.$, $175 \mu \mathrm{m})$ that are slightly out of focus, but not sufficiently to produce a white (Poisson) spot in the middle of the image. For item iii, the error is always in the direction of an overestimation of the size. Therefore we find the maximum overestimation, minimum size, possible by first assuming the effect of (1) above has caused a $10 \mu \mathrm{m}$ overestimate of the apparent size, and then assuming it is also out of focus as much as possible and still not have a spot. The 3rd column in Table 1 is the ratio of the spot size $\left[\left(D_{s}\right)\right]$ to apparent size, (from Korolev, 2007). Using $D_{s}$ of $15 \mu \mathrm{m}$ yields a $Z_{d}$ (normalized distance from the focal plane from Korolev, 2007; Table B1 column 1) and the ratio of apparent size to actual size (from Korolev, 2007; Table B1 column 2, our column 5), from which $D_{o}$ is computed. The maximum underestimation, or maximum possible size, is estimated as $\mathrm{D}_{m}+10$.

\section{B2 CPI images}

Unlike the 2D-S probe, the CPI is designed to maximize detection and imaging of only infocus images. It is, however, possible for CPI images to be out of focus, but unlike the 2D$\mathrm{S}$ probe that has only one gray level (i.e., black), the CPI images particles with 256 gray levels. This significant increase 
in shading allows the eye to readily identify CPI images that are infocus, especially when the images have relatively sharp corners and regular structures, such as the plates shown in Fig. 6 in the text. Thus, uncertainty in the size of infocus CPI images reduces to the pixel size $(2.3 \mu \mathrm{m})$ plus the amount of blur that results from optical aberrations. Based on laboratory evaluation, the amount of blur is estimated to be equivalent to about one pixel, so the total maximum uncertainty in CPI images that are in focus is estimated to be about $5 \mu \mathrm{m}$.

Acknowledgements. We are indebted to the NASA WB-57F crews and SPEC engineers for support of the 2D-S and CPI. J. H. Bain of NASA Johnson Space Center is credited with taking the photograph of the subvisible cirrus layer (Fig. 1) from the back seat of the WB-57F. We are appreciative of the Harvard group, L. Moyer, T. Hanisco and D. Sayres for the ICOS data and Droplet Measurement technologies, D. Baumgardner and G. Kok for the CAPS data. We appreciate insightful comments offered by B. Kärcher, which improved the quality of the manuscript. This research was funded by the NASA Radiation Sciences Program under Grant NNG04GE71G. The 2D-S was recently developed under funding from the US Navy Office of Naval Research Contract N00014-02-C-0317.

Edited by: T. Koop

\section{References}

Baker, B. A. and Lawson, R.P.: Improvement in determination of ice water content from two-dimensional particle imagery: Part I: Image to mass relationships, J. Appl. Meteorol., 45, 1282-1290, 2006.

Barrett, E. W., Herndon, L. R., and Carter, H. J.: Some measurements of the distribution of water vapor in the stratosphere, Tellus, 2, 302-311, 1950.

Baumgardner, D., Dye, J. E., Knollenberg, R. G., and Gandrud, B. W.: Interpretation of measurements made by the FSSP-300X during the Airborne Arctic Stratospheric Expedition, J. Geophys. Res., 97, 8035-8046, 1992.

Baumgardner, D., Jonsson, H., Dawson, W., O'Connor, D., and Newton, R.: The cloud, aerosol and precipitation spectrometer: a new instrument for cloud investigations, Atmos. Res., 59-60, 251-264, 2001.

Beyerle, G., Schäfer, H.-J, Neuber, R., Schrems, O., and McDermid, I. S.: Dual wavelength lidar observation of tropical high altitude cirrus clouds during the ALBATROSS campaign, Geophys. Res. Lett., 25, 919-922, 1996.

Brewer, A. W.: Evidence for a world circulation provided by the measurements of helium and water vapor distribution in the stratosphere, Q. J. Roy. Meteor. Soc., 75, 351-363, 1949.

Clark, H. L.: Longitudinal variability of water vapor and cirrus in the tropical tropopause layer, J. Geophys. Res., 110, D07107, doi:10.1029/2004JD004943, 2005.

Comstock, J. M., Ackerman, T. P., and Mace, G. G.: Ground based remote sensing of tropical cirrus clouds at Nauru Island: Cloud statistics and radiative impacts, J. Geophys. Res., 107(D23), 4714, doi:10.1029/2002JD002203, 2002.
Field, P. R., Wood, R., Brown, P. R. A., Kaye, P. H., Hirst, E., Greenaway, R., and Smith, J. A.: Ice particle interarrival times measured with a fast FSSP, J. Atmos. Oceanic Technol., 20, 249261, 2003.

Field, P. R., Heymsfield, A. J., and Bansemer, A.: Shattering and Particle Interarrival Times Measured by Optical Array Probes in Ice Clouds, J. Atmos. Oceanic Technol., 23, 1357-1371, 2006.

Folkins, I., Loewenstein, M., Podolske, J., Oltmans, S. J., and Proffitt, M.: A $14 \mathrm{~km}$ mixing barrier in the tropics: Evidence from ozonesondes and aircraft measurements, J. Geophys. Res., 104, 22 095-22 102, 1999.

Gierens, K. M., Schumann, U., Helten, M., Smit, H., and Marenco, A.: A distribution law for relative humidity in the upper troposphere and lower stratosphere derived from three years of MOZAIC measurements, Ann. Geophys., 17, 1218-1226, 1999, http://www.ann-geophys.net/17/1218/1999/.

Goldfarb, L., Keckhut, P., Chanin, M.-L., and Hauchecorne, A.: Cirrus climatological results from lidar measurements at OHP (44_ N, 6_ E), Geophys. Res. Lett., 28, 1687-1690, 2001.

Heymsfield, A. J.: Ice particles observed in a cirriform cloud at $-83^{\circ} \mathrm{C}$ and implications for polar stratospheric clouds, J. Atmos. Sci., 43, 851-855, 1986.

Immler, F. and Schrems, O.: LIDAR measurements of cirrus clouds in the northern and southern midlatitudes during INCA $\left(55^{\circ} \mathrm{N}\right.$, $53^{\circ} \mathrm{S}$ ): A comparative study, Geophys. Res. Lett., 29, 1809, doi:10.1029/2002GL015077, 2002.

Jensen, E. J., Toon, O. B., Pfister, L., and Selkirk, H. B.: Dehydration of the upper troposphere and lower stratosphere by subvisible cirrus clouds near the tropical tropopause, Geophys. Res. Lett., 23, 825-828, 1996.

Jensen, E. J., Read, W. G., Mergenthaler, J., Sandor, B. J., Pfister, L., and Tabazadeh, A.: High humidities and subvisible cirrus near the tropical tropopause, Geophys. Res. Lett., 26, 23472350, 1999.

Jensen, E. J., Toon, O. B., Vay, S. A., Ovarlez, J., May, R., Bui, P., Twohy, C. H., Gandrud, B., Pueschel, R. F., and Schumann, U.: Prevalence of ice-supersaturated regions in the upper troposphere: Implications for optically thin ice cloud formation, J. Geophys. Res., 106, 17 253-17 266, 2001.

Jensen, E. J. Smith, J. B., Pfister, L, Pittman, J. V., Weinstock, E. M., Sayres, D. S., Herman, R. L., Troy, R. F., Rosenlof, K., Thompson, T. L., Fridlind, A. M., Hudson, P. K., Cziczo, D. J., Heymsfield, A. J., Schmitt, C., and Wilson, J. C.: Ice supersaturations exceeding $100 \%$ at the cold tropical tropopause: implications for cirrus formation and dehydration, Atmos. Chem. Phys., 5, 851862,2005 , http://www.atmos-chem-phys.net/5/851/2005/.

Jensen, E. J., Pfister, L., Bui, T. V., Lawson, P., Baker, B., Mo, Q., Baumgardner, D., Weinstock, E. M., Smith, J. B., Moyer, E. J., Hanisco, T. F., Sayres, D. S., Clair, J. M. St., Alexander, M. J., Toon, O. B., and Smith, J. A.: Formation of large $(\simeq 100 \mu \mathrm{m})$ ice crystals near the tropical tropopause, Atmos. Chem. Phys., 8, 1621-1633, 2008, http://www.atmos-chem-phys.net/8/1621/2008/.

Kärcher, B. and Solomon, S.: On the composition and optical extinction of particles in the tropopause region, J. Geophys. Res., 104, 27 441-27 459, 1999.

Koop, T., Luo, B. P., Tsias, A., and Peter, T.: Water activity as the determinant for homogeneous ice nucleation in aqueous so- 
lutions, Nature, 406, 611-614, 2000.

Korolev, A. V., Strapp, J. W., and Isaac, G. A.: Evaluation of the accuracy of PMS optical array probes, J. Atmos. Oceanic Technol., 15, 708-720, 1998.

Korolev A. V. and G. A. Isaac.: Shattering during Sampling by OAPs and HVPS. Part I: Snow Particles, J. Atmos. Oceanic Technol. 22, 528-542, 2005.

Korolev, A. V.: Reconstruction of the sizes of spherical particles from their shadow images. Part I: Theoretical considerations, J. Atmos. Oceanic Technol., 24, 376-389, 2007.

Lawson, R. P., Baker, B. A., Schmitt, C. G., and Jensen, T. L.: An overview of microphysical properties of Arctic clouds observed in May and July during FIRE.ACE, J. Geophys. Res., 106, 14 989-15 014, 2001.

Lawson, R. P., O'Connor, D., Zmarzly, P., Weaver, K., Baker, B. A., Mo, Q., and Jonsson, H.: The 2D-S (Stereo) probe: design and preliminary tests of a new airborne, high speed, high-resolution particle imaging probe, J. Atmos. Oceanic Technol., 23, 14621477, 2006.

Lelieveld, J., Bregman, A., Scheeren, H. A., Ström, J., Carslaw, K. S., Fischer, H., Siegmund, P. C., and Arnold, F.: Chlorine activation and ozone destruction in the northern lowermost stratosphere, J. Geophys. Res., 104, 8201-8213, 1999.

Macke, A., Francis, P. N., McFarquhar, G. M., and Kinne, S.: The role of ice particle shapes and size distributions in the single scattering properties of cirrus clouds, J. Atmos. Sci., 55, 2874-2883, 1998.

May, R. D.: Open path, near-infrared tunable diode laser spectrometer for atmospheric measurements of $\mathrm{H}_{2} \mathrm{O}$, J. Geophys. Res., 103, 19 161-19 172, 1998.

McFarquhar, G. M., Heymsfield, A. J., Spinhirne, J., and Hart, B.: Thin and subvisual tropopause tropical cirrus: Observations and radiative impacts, J. Atmos. Sci., 57, 1841-1853, 2000.

Murphy, D. M., Kelly, K. K., Tuck, A. F., Proffitt, M. H., and Kinne, S.: Ice saturation at the tropopause observed from the ER-2 aircraft, Geophys. Res. Lett., 17, 353-356, 1990.

Murphy, D. M., Cziczo, D. J., Froyd, K. D., Hudson, P. K., Matthew, B. M., Middlebrook, A. M., Peltier, R. E., Sullivan, A., Thomson, D. S., and Weber, R. J., Single-particle mass spectrometry of tropospheric aerosol particles, J. Geophys. Res., 111, D23S32, doi:10.1029/2006JD007340, 2006.

Oltmans, S. J., Vömel, H., Hofmann, D. J., Rosenlof, K. H., and Kley, D.: The increase in stratospheric water vapor from balloonborne, frostpoint hygrometer measurements at Washington, D.C. and Boulder, Colorado, Geophys. Res. Lett., 27, 3453-3456, 2000.

Ovarlez, J., van Velthoven, P., Sachse, G., Vay, S., Schlager, H., and Ovarlez, H.: Comparisons of water vapor measurements from POLINAT 2 with ECMWF analyses in high-humidity conditions, J. Geophys. Res., 105, 3737-3744, 2000.
Ovarlez, J., Gayet, J.-F., Gierens, K., Ström, J., Ovarlez, H., Auriol, F., Busen, R., and Schumann, U.: Water vapour measurements inside cirrus clouds in Northern and Southern hemispheres during INCA, Geophys. Res. Lett., 29, 29(16), 1813, doi:10.1029/2001GL014440, 2002.

Peter, T., Luo, B. P., Wenrli, H., Wirth, M., Kiemle, C., Flentje, H., Yushkov, V. A., Khattatov, V., Rudakov, V., Boormann, A. T., Toci, G., Mazzinghi, P., Beuermann, J., Schiler, C., Cairo, F., Don-Francesco, G. D., Adriani, A., Volk, C. M., Strom, J., Noone, K., Mitev, V., MacKenzie, R. A., Carslaw, K. S., Trautmann, T., Santacesaria, V., and Stefanutti, L.: Ultrathin Tropical Tropopause Clouds (UTTCs): I. Cloud morphology and occurrence, Atmos. Chem. Phys., 3, 1557-1578, 2003, http://www.atmos-chem-phys.net/3/1557/2003/.

Peter, T., Marcolli, C., Spichtinger, P., Corti, T., Baker, M. B., and Koop, T.: When Dry Air Is Too Humid, Science, 314, 13991402, 2006.

Sassen, K. and Campbell, J. R.: A midlatitude cirrus cloud climatology from the facility for atmospheric remote sensing. Part I: Macrophysical and synoptic properties, J. Atmos. Sci., 58, 481496, 2001.

Sayres, D. S.: New techniques for accurate measurement of water and water isotopes, Ph.D. Thesis, Harvard University, Cambridge, MA., 2006.

Scott, S. G., Bui, T. P., Chan, K. R., and Bowen, S. W.: The meteorological measurement system on the NASA ER-2 aircraft, J. Atmos. Ocean. Technol., 7, 525-540, 1990.

Stephens, G. L., Tsay, S.-C., Stackhouse, P. W., and Flatau, P. J.: The relevance of the microphysical and radiative properties of cirrus clouds to climate and climatic feedback, J. Atmos. Sci., 47, 1742-1753, 1990.

Thomas, A., Borrmann, S., Kiemle, C., Cairo, F., Volk, M., Beuermann, J., Lepuchov, B., Santacesaria, V., Matthey, R., Rudakov, V., Yushkov, V., MacKenzie, A. R., and Stefanutti, L.: In situ measurements of background aerosol and subvisible cirrus in the tropical tropopause region, J. Geophys. Res., 107, 4763, doi:10.1029/2001JD001385, 2002.

Wang, P.-H., Minnis, P., McCormick, M. P., Kent, G. S., and Skeens, K. M.: A 6-year climatology of cloud occurrence frequency from Stratospheric Aerosol and Gas Experiment II observations (1985-1990), J. Geophys. Res., 101, 29 407-29429, 1996.

Weinstock, E. M., Hintsa, E. J., Dessler, A. E., Oliver, J. F., Hazen, N. L., Demusz, J. N., Allen, N. T., Lapson, L. B., and Anderson, J. G.: New fast response photofragment fluorescence hygrometer for use on the NASA ER-2 and the Perseus remotely piloted aircraft, Rev. Sci. Instrum., 22, 3544-3554, 1994.

Wendisch, M., Yang, P., and Pilewskie, P.: Effects of ice crystal habit on thermal infrared radiative properties and forcing of cirrus, J. Geophys. Res., 112, D08201, doi:10.1029/2006JD007899, 2007. 